Portland State University

PDXScholar

\title{
Hidden in Plain Sight: Findings from a Survey on the Multi-Major Professional Writing Course
}

\author{
Sarah Read \\ Portland State University, read3@pdx.edu \\ Michael J. Michaud \\ Rhode Island College
}

Follow this and additional works at: https://pdxscholar.library.pdx.edu/eng_fac

Part of the Curriculum and Instruction Commons, Educational Methods Commons, and the Scholarship of Teaching and Learning Commons

Let us know how access to this document benefits you.

\section{Citation Details}

Read, Sarah and Michaud, Michael J., "Hidden in Plain Sight: Findings from a Survey on the Multi-Major Professional Writing Course" (2018). English Faculty Publications and Presentations. 25.

https://pdxscholar.library.pdx.edu/eng_fac/25

This Post-Print is brought to you for free and open access. It has been accepted for inclusion in English Faculty Publications and Presentations by an authorized administrator of PDXScholar. Please contact us if we can make this document more accessible: pdxscholar@pdx.edu. 
Hidden in Plain Sight

Hidden in Plain Sight: Findings from a Survey on the Multi-Major Professional Writing Course

Sarah Read, Department of English, Portland State University.

Michael Michaud, Department of English, Rhode Island College.

This research was supported by a Research Initiative Grant from the Conference on College Composition and Communication.

Correspondence concerning this article should be addressed to Sarah Read, Department of English, Portland State University PO Box 751, Portland, OR, 97207-0751.

Contact:read3@pdx.edu

Sarah Read

Portland State University

Michael Michaud

Rhode Island College

\section{ABSTRACT}

In this article, we report on findings from a survey of writing instructors who teach the multimajor professional writing course (MMPW) across diverse institutional contexts. We 
marshal these findings to advance a series of arguments about the situation of the MMPW course in U.S. higher education.

Keywords: survey research, programmatic research

\section{INTRODUCTION}

With some variation, the following course title and description can be found in college and university catalogs across the broad institutional landscape of U.S. higher education:

Introduction to Technical/Professional Writing: Introduces technical and professional communications. Students compose, design, revise, and edit effective letters, memos, reports, descriptions, instructions, and employment documents. Emphasizes precise use of language and graphics to communicate complex technical and procedural information safely, legally, and ethically.

Descriptions such as this are recognizable by students, faculty, and administrators as a normal part of the writing curriculum at most colleges and universities. Its broadness and muddiness of scope are neatly signified by the "slash" construction of the course title, which conflates two related but distinct subfields: technical and professional writing. Although the course this description promises broad recognition in terms of its value to the curriculum, the ease with which it fulfills the expectations of its stakeholders has tended to foreclose the possibility of critical conversation about it.

One of the consequences of the normalization of descriptions like the one above is a dearth of disciplinary attention paid to the status of courses like Introduction to 
Technical/Professional Writing (beyond pedagogical innovations and/or local institutional issues and concerns). By invoking the notion of status, we mean to address more than whether this course is afforded low or high prestige by whichever stakeholders are in a position to proffer such a judgment. Asking about status is really a way of asking, "What is going on with this course given the present circumstances?" For example, a project team would prepare a status update of a large and complex project.

The notion of status is useful because it is broad and capacious, allowing inquiry into contemporary circumstances related to the course that have not previously been studied in a systematic way. Such inquiry can provide a foundation for a focused disciplinary conversation that we feel is long overdue. In this article, we initiate this conversation by reporting on results of a survey of writing instructors who teach what we call the multimajor professional writing course (MMPW). (Our survey instrument can be found in the Appendix). In what follows, we report on findings from our survey and marshal them to make arguments about the status of the MMPW course in U.S. higher education.

\section{What is the MMPW Course?}

The term multimajor professional writing, or MMPW, is our adaptation of what Kain and Wardle (2005) have termed "multi-major (or perhaps multi-professional) communication courses" (p. 114). The MMPW course exists in a wide range of forms in many, if not most, postsecondary settings. Although it appears in many instantiations, we understand it to be a survey/introduction to professional writing as a mode of communication that is decontextualized from any specific knowledge or professional domain (e.g., engineering, medicine, or a 
specialized business profession). MMPW courses are usually taken as service classes by students from across the university at all levels of degree completion and often also as electives by English or Writing majors and minors.

The broadness of our definition of the MMPW course reflects the difficulty previous researchers have encountered when trying to categorize or define curricula or programs in business, professional, and technical writing. Sullivan and Porter (1993), for example, acknowledge the difficulty of defining the boundaries between business, professional, and technical writing, and fashion a definition for professional writing that is nearly as inclusive as ours: "a course or course offered, usually by the department of English, as a service to other disciplines in the university; often, loosely equated with business and/or technical writing" (p. 392). Yeats and Thompson (2010) developed a continuum for identifying the curricular focus of technical and professional communication (TPC) programs, yet, not surprisingly, found that that the idiosyncratic nature of programs based on local variation overwhelmed their attempt to categorize program types more systematically. Our own review of the 152 MMPW course titles and descriptions provided to us by our survey respondents revealed that of the 114 titles and descriptions that deployed at least one of the terms business, technical, scientific, workplace, and/or professional, 57, exactly half, used more than one of these terms, often deploying them interchangeably.

Given these definitional problems, we assumed that the variation Sullivan and Porter (1993) and Yeats and Thompson (2010) found in their studies is reflected in the introductory MMPW course. To avoid the inevitable conclusion that variation in the course across 
institutional types and variation in the institutional history of the course overwhelms systematic categorization or study, we chose to acknowledge this variation as a baseline for our survey and to set the definition for our unit of analysis to be broad enough to accommodate most of this variation. We felt that despite the variation in this introductory service course, including its name (business? technical? professional?), curricular focus, and institutional situation, enough commonality exists to warrant a study that assumed a singular entity within which variation is expected and normalized.

\section{Why Study the MMPW Course?}

One of the main reasons to study the MMPW course is because it is likely the second-most ubiquitous writing course in U.S. higher education, after first-year composition (FYC). And yet, despite its ubiquity, the MMPW course lacks most of the institutional recognition and professional infrastructure that has grown up around FYC. Although real numbers are not available for the total number of sections taught annually of either the MMPW course or FYC, we have made educated estimates based on data that is available from Carnegie Classification of Institutions of Higher Education (CCIHE; CCIHE, 2016a), The National Writing Census, and our survey. We conservatively estimate that there are about $40,000^{1}$ (rounded to the closest ten thousand) sections of the MMPW course taught each year in the U.S. across all institutional types and about $200,000^{2}$ (rounded to the closest ten thousand) sections of FYC. Even though FYC sections outnumber MMPW sections by approximately 5 to 1 , we can't think of another writing course that approaches this level of ubiquity, with the possible exception of academic English courses for second language students. Regardless, MMPW courses consume a 
substantial amount of institutional and faculty investment—an amount that more than warrants a study of the course's status.

\section{What is Already Known about the MMPW Course?}

Despite its ubiquity, and the acknowledgement that the origins of technical and professional communication (TPC) in the academy are in the MMPW course (Staples, 1999), little is known about the status of the course laterally across institutional contexts. This is because, historically, the MMPW course has existed at the periphery of the curricular and intellectual projects of English departments and other institutional sponsors (i.e., engineering schools or independent departments of rhetoric and writing). Although the ubiquity of the course expanded rapidly during the post-WWII era, with the growth of engineering programs in higher education, the course suffered from "status-driven polarities" (Staples, 1999, p. 161) that ensured that the course was taught by low-status members of English departments such as graduate students and adjuncts who had little to no incentive to do research on the course. Data gathered in 2009 suggested that as much as $83 \%$ of TPC service courses were taught by contingent faculty (Meloncon \& England, 2011, p. 405). Whether because of lack of stakeholders' motivation in the course or its low status in English studies, systematic research into the MMPW course remained a risky endeavor for scholars in the emerging field of technical and professional communication. As a result, the MMPW course has not often been studied as a unit of analysis across the diversity of institutional contexts in which it is taught.

Since the postwar period of expansion, the field of TPC has, with success, invested a great deal in the development of graduate and undergraduate degree programs and certificates to 
raise the field's institutional and professional profile. This investment has resulted in dramatic growth of academic programs in TPC (Meloncon, 2012; Meloncon \& Henschel, 2013). This investment is also evidenced by the focus of previously published survey-based studies, which chart the development of disciplinary apparatus, such as undergraduate majors and minors, graduate programs, and certificates (Allen \& Benninghoff, 2004; Reave, 2004; Yeats \& Thompson, 2010), and the profiles of the members of the Association of Teachers of Technical Writing (ATTW) professional organization (Dayton \& Bernhardt, 2004). In none of these studies, however, is the MMPW the unit of analysis. The previous survey studies that are most closely related to the MMPW course focus on TPC textbooks (McKenna \& Thomas, 1997; Warren, 1996), which are primarily in use in introductory-level courses, and the status of contingent faculty in TPC (Meloncon \& England, 2011). These studies, however, are not based on the systematic collection of survey data from stakeholders, but, instead, are "surveys" in the sense of overviews based on the historical development of the course or data that is available online, such as an online schedule of classes.

We also want to acknowledge that there is an extensive literature developing the curriculum and pedagogy for the TPC service course in journals such as Technical Communication Quarterly, Journal of Business and Technical Communication, Journal of Technical Writing and Communication, Technical Communication, and, to a lesser extent, College Composition and Communication and other composition journals. The depth and variety of this literature (e.g., Blakeslee, 2001; Kain \& Wardle, 2005; Read \& Michaud, 2015; Spinuzzi, 1996; Wickliff, 1997) lends the impression that the MMPW course has been a focus of research interest; however, the majority of this literature focuses on pedagogical practices or curricular 
developments and not on the status of the course as a unit of analysis unto itself. As important as the study and development of teaching practices and curricula are, these types of studies do not document or account for aspects of the course that we report on in this article, such as institutional situation and how confident instructors are in the course.

Our survey study assumed that the MMPW course is a unit of analysis that can be studied laterally across institutional types and contexts. Because of this assumption, our study was a robust, but preliminary, effort to survey instructors and to investigate the question "What is the status of the multimajor professional writing (MMPW) course?" The results of such a study provide a macrolevel view of who teaches the course, its institutional situation, common pedagogical practices, and perceptions of the effectiveness of the course. The value of this view is that it can motivate discussion at the level of the field's professional organizations about ways to develop and invest in the MMPW course so as to ensure that it remains relevant and responsive to changes in the 21 st-century academy and economy.

\section{METHODOLOGY}

Given the ubiquity of the MMPW course across all contexts of higher education, we chose to make the principal design choice of our methodology a commitment to proportional representation among respondents by the type of institution where they primarily teach an MMPW course (e.g., associate's colleges, master's colleges and universities, doctorate-granting institutions, tribal colleges). This methodology generally reflects that of Meloncon and England's (2011) study of contingent faculty in TPC, which drew data on the rank of instructors teaching the TPC service course across six Carnegie classifications of 4-year institutions. 
However, we wanted our survey data to reflect the experiences and views of MMPW instructors across the diversity of 2- and 4-year postsecondary contexts. Toward these ends, we used data published by the CCIHE (2016b) to set quotas for respondent recruitment by institutional type from the overall population of MMPW instructors. We used CCIHE's six postsecondary institutional types for 2-year and 4-year institutions and reported proportional representation of student enrollment at each institutional type (see Table 1). In addition, we set our recruitment goal at 150 completed surveys. Random sampling, the ideal technique in social science research, was not possible because this study recruited from a population that is not centrally documented. Nonrandom techniques such as convenience sampling are often used when data supports exploratory analysis (Kelley, Clark, Brown, \& Sitzia, 2003) or when results will not be generalized to the larger population using inferential statistics (Banerjee \& Chaudhury, 2010).

When disseminating our survey, we faced challenges recruiting instructors from a population that is not centrally documented (such as in a directory). Given the lack of a census of this population, our sample was what social scientists call a convenience sample. This means that we recruited respondents from the population via channels that we had access to given our own professional affiliations and connections. The channels included the email listservs of professional organizations in the field, the social media sites of the National Council of Teachers of English (NCTE) college section, emails to colleagues requesting assistance distributing the survey link, and a small number of personalized emails to instructors who are particularly hard to reach, such as those at tribal colleges. To aid in recruitment, we offered a modest incentive in the form of a $\$ 5$ coffee card to all who completed our survey. ${ }^{3}$ In total, 220 respondents consented to take the survey and 154 respondents completed the survey in its entirety (a 70\% completion 
rate). To keep our " $N$ " consistent across all survey questions, we excluded the incomplete surveys from our data during the analysis phase (see Table 1).

\section{INSERT TABLE 1 HERE}

In addition to proportional institutional representation, we also aimed for diversity in the faculty rank of survey respondents. We did not set formal quotas here since we knew that our recruitment techniques would necessarily be biased toward respondents who are the most professionally active. As a rough guide, however, we used data from the American Association of University Professors (AAUP) on the national percentage of all instructional staff by employment status to put our response rates by faculty rank into perspective (Curtis, 2014; see Table 2). The nontenure-track representation (50\%), including both full-time and part-time instructors and graduate students, exceeded the tenure-track representation (38\%), ensuring that nontenure-track respondents had a strong voice in the aggregate survey data.

\section{INSERT TABLE 2 HERE}

Because we were able to meet our recruitment goals within a reasonable range, we feel comfortable that our survey data generally reflects the broad experiences and views of MMPW instructors across institutional contexts and faculty ranks.

A second important issue we confronted when designing our study had to do with defining the notion of status, the pivotal term in our research question. For the purpose of this survey, we articulate status to include both descriptive and subjective components. Descriptive 
components include aspects of the course that reflect its current situation in a local institutional context:

- Who teaches the course and how

- Who takes the course and why

- What kinds of materials are used to teach the course (i.e., textbooks, technology)

- How the course is situated institutionally

- What kinds of professional and institutional investments go into the course.

The subjective component of status includes the assessment of instructor confidence in the effectiveness of the course:

- $\quad$ Student satisfaction

- $\quad$ Levels of student learning

- $\quad$ Levels of meeting student expectations

- $\quad$ Levels of the course meeting stated objectives

- Levels of resource availability and support for instructors

- $\quad$ Effectiveness of the course in meeting larger curricular goals for students and programs. 
Additionally, the subjective assessment portion of "status" includes instructors' perceptions of how the course can be improved (e.g., common outcomes, more opportunities for professional development, new textbooks, etc.). In sum, in investigating the status of the MMPW course, we are interested in trying to understand both the many and diverse conditions under which it is taught and the subjective perceptions of those who teach it.

We designed and built our survey using the online survey tool Qualtrics. Forty-five questions on our survey supported the descriptive component, the majority of which were multiple choice (several, though, offered opportunities for write-in answers). In the descriptive arena, we asked respondents about the institutional, curricular, and faculty situation of the course as they understood it in their local context. The subjective component of the survey was comprised of eight questions that prompted respondents to report on their level of confidence in various aspects of the course. Respondents moved a slider along a scale from zero to 100, with zero indicating "not at all confident," 50 indicating "sort of confident," and 100 indicating "fully confident." The default position of the slider was set to the middle position, 50, "sort of confident," which we understood to reflect a position of ambivalence or uncertainty, to encourage respondents to clarify their level of confidence in one direction or the other. This turned out to be a crucial design decision for our analysis of survey data (more on this below). Finally, in the subjective section of the survey, we asked respondents to sort a list of 13 items according to whether they would improve their confidence in the course. Respondents sorted items into boxes marked "would definitely help," "would help a little," "would make no difference," "already doing," and "not relevant." We concluded the survey by offering respondents the chance to share any information about the course and their experience of 
teaching it that we may have failed to solicit. To ensure that our survey would gather the data we intended and be maximally user-friendly for respondents, we user tested it during the winter and early spring of 2015 and obtained approval from the Internal Review Board at both our institutions.

In what follows, our intent is to provide descriptive evidence of patterns in the response data. Rather than present our data in a linear fashion or in the order in which it was collected in our survey, we have marshaled key findings in strategic ways so as to advance a series of arguments about the status of the MMPW course in U.S. higher education. At every turn, we have recognized the limitations of our data and resisted inferring causation for results or generalization to a broader population (which remains undocumented). Within these limitations, we believe that our data based on a quota-based convenience sample is adequate for initiating a conversation within the field about the implications our study.

In this article, we begin by drawing on the descriptive data to make an argument about what we discovered to be a persistent conservatism in the teaching of the course. We then move on to the subjective data to discuss the implications of respondents' varying levels of confidence in the course, especially in regard to the preparedness of the course's instructor corps. We close by discussing the implications of our findings for key stakeholders.

\section{FINDINGS}

In this section of our article, we share findings on the status of the MMPW course, organized along three lines of inquiry that emerged as salient from our survey data: 
- What pedagogical approaches shape the teaching of the MMPW course?

- How confident are instructors in the MMPW course?

- What would improve instructor confidence in the MMPW course?

\section{What Pedagogical Approaches Shape the Teaching of the MMPW}

\section{Course?}

When investigating the role of pedagogy in the MMPW course, we began with our own experiences, which suggest that the pedagogical choices writing instructors make in their classrooms are complex, evolving, and multifaceted. As Tate, Tagart, Schick, and Hessler (2013) write in their "Introduction" to A Guide To Composition Pedagogies, "rare is the teacher who does not blend the practices of many pedagogical philosophies" (p. 6). With this in mind, we set about trying to learn more about the pedagogies that shape MMPW instruction. First, we asked about the teaching materials instructors use. Next, we asked about the pedagogical approaches they draw on. Finally, hoping to learn about the ways in which instructors, departments, and institutions articulate MMPW pedagogies to themselves, students, parents, and other stakeholders, we asked respondents to share with us the title and catalogue description of the MMPW course they teach. Let's take these one at a time.

Although our respondents indicated that they utilize a range of teaching materials in MMPW classes (i.e., online handbooks, general and business periodicals, scholarly articles, etc.), 
$92 \%$ use a textbook to teach the course. This finding, as Table 3 shows, is consistent across most institutional types.

\section{INSERT TABLE 3 HERE}

The finding that a majority of survey respondents utilize a textbook may not be surprising. As Warren (1996) notes in his survey of technical writing textbooks from 1950-1970, "The textbook is the main teaching tool for instructors" (p. 155). Connors (1982), too, has shown how textbooks have historically been the primary teaching tool of MMPW instructors. In addition to learning whether or not respondents utilize a textbook, though, we were also interested in the degree of autonomy they have to choose their textbook. Our survey results show that just under two-thirds $(62 \%)$ of respondents who indicated that they use a textbook also indicated that they choose their own book (see Table 4).

\section{INSERT TABLE 4 HERE}

Interestingly, when we looked at the question of why respondents chose a textbook, we found that greater flexibility and choice seem to be granted to instructors teaching at bachelor's $(100 \%$ choose text), master's colleges and universities (87\% choose text), and doctorate-granting institutions ( $78 \%$ choose text) than at associate's colleges $(60 \%$ choose text; see Table 5$)$.

\section{INSERT TABLE 5 HERE}

The finding that almost two-thirds of survey respondents choose their own textbook seems to suggest a high level of autonomy in devising pedagogies to teach their courses. At the same time, the fact that so many respondents use a textbook suggests that textbooks may exert a powerful 
influence over the curriculum and pedagogy of MMPW courses. This fact makes an investigation into which textbooks MMPW instructors use critical. Before we get to our findings on textbookuse, though, we would like to offer this qualification: We are aware that textbooks have a varying degree of influence over the curriculum and pedagogy of a writing class. Although some instructors may follow the outline of a textbook to the letter, others might dip into a book now and again to touch on certain topics or use the book behind the scenes as a resource for planning lessons. In sum, we are well aware that it is difficult to draw firm conclusions about textbook-use from survey data that indicate only textbook-selection.

Having said this, the survey asked respondents to identify the textbook they use from a list of nine titles that we created based on our own anecdotal knowledge of popular titles in the field. Table 6 lists the nine books as well as the percentage of respondents who indicated that they use each title.

\section{INSERT TABLE 6 HERE}

We note that though nearly half (43\%) of those who indicated that they use a textbook do not use a book on our list, nearly half $(43 \%)$ use one of five well-known textbooks: Technical Communication (Markel, 2014); Writing That Works (Oliu, Brusaw, \& Alred, 2016); Essentials of Technical Communication (Tebeaux \& Dragga, 2014); Technical Communication Strategies for Today (Johnson-Sheehan, 2014); Successful Writing at Work (Kolin, 2012). Each of these five textbooks deploys what we have identified in another section of our survey as a "Communications Genres" approach to the teaching of MMPW. This approach walks students through a fairly stable and, as historical studies of professional writing instruction have shown 
(see Connors, 1982), well-established roster of professional document types (e.g., memos, letters, proposals, reports, etc.). The pervasiveness of this approach as it is formalized across the most commonly used textbooks raises the question of whether these textbooks are still in touch with research in the field of professional and technical communication and the realities of 21 stcentury knowledge-based communications practices. This is a larger question that can only be initiated by our analysis here and would require more in-depth analysis to pursue further.

Because we assumed that textbook-choice offers only a limited window into instructors' pedagogical practice, we also asked survey respondents to report on their approach to teaching the MMPW course, giving them the chance to choose from a list of common approaches gathered from our experience and the scholarly literature. Respondents first identified any/all of the approaches that they draw on when teaching MMPW courses and then were asked to identify their primary or central approach from the same list of possibilities. (See Tables 7 and 8.)

\section{INSERT TABLE 7 HERE}

\section{INSERT TABLE 8 HERE}

Overall, our prediction, based on the results of our textbook questions, that a genre-based approach is pervasive in the teaching of MMPW among respondents, was supported by the data. We found that the Teaching Communication Genres approach was both the most frequently chosen approach (88\% of respondents) and the most frequently chosen primary or central approach (51\% of respondents). Interestingly, we found that these results remained largely consistent across all institutional types. For example, we did not find significant variations in the 
frequencies of approaches chosen between respondents from doctorate-granting and associate's institutions.

We note that the second most common teaching approach among our survey respondents is Teaching Professional Development Genres (68\%), which is an approach that also focuses on explicit instruction in specific genres of writing (i.e., cover letters, resumes). Instruction in both communications genres and professional development genres is a component of all five of the most commonly used MMPW textbooks, and these findings about approach are consistent across all institutional types.

Other notable findings from our questions about pedagogical approach include the finding that two-thirds of respondents $(66 \%)$ indicate that "teaching students how to do their own research about writing in workplace contexts" is an element of their pedagogy and that just over half of all respondents connect their MMPW students with professional writing contexts external to the college/university ( $28 \%$ engage students in client-centered work and $33 \%$ engage them in service-learning projects). The relatively robust frequencies for these alternate approaches are tempered by the fact that only $14 \%$ of respondents identify one of these two approaches as their central or primary approach. Finally, we note that though $48 \%$ of respondents, almost half, indicate that they engage students in reading scholarly texts and experimenting with scholarly research methods, an approach we advance (Read \& Michaud, 2015), only 9\% identify this approach as their central or primary one.

A final and admittedly more complicated means of gathering data on the pedagogies of MMPW courses comes from the course titles and descriptions that instructors, 
programs/departments, and institutions create to communicate to themselves, students, parents, and other stakeholders the content and approach of their MMPW course. Our initial review of course titles and descriptions confirmed the complexity of using them as a means of understanding pedagogical concerns - there were simply too many variations in terms to create stable categories of analysis. However, given the emerging picture in our data about the prevalence of the formalist, genre-based approach, we limited our analysis of the course description data to a single question, asking whether course descriptions explicitly specified that students would be exposed to or taught prototypical workplace communication genres (e.g., memos, letters, proposals, and reports). We found that 69 out of the 91 descriptions we analyzed, or $76 \%$, explicitly mentioned that communications genres would be covered in the course. We feel that this number is meaningful and that it further illustrates the extent to which Teaching Communications Genres is an important element of our survey respondents' pedagogical approach to teaching the MMPW course.

Our findings under the banner of the question: "What pedagogical approaches shape the teaching of the MMPW course?" lead us to suggest that there are persistent norms among respondents for pedagogical approach and choice of teaching materials in MMPW instruction that are shaped by what have been known generally as current-traditional rhetorical (CTR) practices. Although we are aware that importing the disciplinarily loaded term CTR into a discussion of MMPW pedagogies is fraught with complication, we ground our use of this term in Crowley's (1998) articulation of CTR as a pedagogy that "resists changes in its rules and preserves established verbal traditions and institutional lines of authority" (p. 218). We note that all three sources of evidence we examined to investigate pedagogical considerations - choice of 
textbook, choice of teaching approach, and description of course content and approach — suggest the prevalence of a largely formalist, genre-driven approach to the teaching of MMPW among respondents.

\section{How Confident are MMPW Instructors in the MMPW Course?}

Part of our motivation for undertaking this survey project was to document how respondents felt about the MMPW course. In addition, we wanted to prompt respondents to think beyond their own experiences with the course and to get an idea of their confidence in the whole enterprise of the MMPW course at their institution. We were motivated to conduct what we called the "subjective assessment" portion of the survey because of our own personal suspicions, based on experience and anecdotal evidence, that we would find a gap between the confidence that instructors of the MMPW course have in their own instantiations of the course and their confidence in the enterprise of the MMPW at their institution in general. In this section of the article we will share our findings from the subjective assessment portion of the survey and discuss what they can mean for how we understand the status of the MMPW course.

The subjective section of the survey was comprised of eight questions that each prompted the respondent to record his or her level of confidence in an aspect of the MMPW course by moving a slider to an acceptable position along a scale from not at all confident (0) to fully confident (100). The slider default was set to the middle position of sort of confident (50). Each

of the slider prompts was a statement in which respondents rated their level of confidence. The first prompt asked respondents to record their "overall confidence in the effectiveness of the MMPW." The seven following statements addressed narrower aspects of the MMPW course. 
These statements fell into three categories of factors related to the course: students, instructors, and institutions. This design created internal consistency for the survey and also meant that descriptive data from the first part of the survey could be used to better understand the subjective data from the second part of the survey. Table 9 lists the eight slider prompts and the average slider position (on a scale from 0 to 100 ) across all respondents for each prompt, broken out by student, instructor and institutional factors.

\section{INSERT TABLE 9 HERE}

At first glance, Table 9 tells a uniformly positive story. First, across all of the prompts, the average of all respondents' ratings is above 50 (sort of confident). What this means is that when responses from all survey respondents are considered collectively the overall picture is one of moderately high confidence. This is true across all the categories of factors, from overall confidence in the course (Q62: average 67), to confidence in whether students are readier to write in the workplace after taking the course (Student factors; Q38_2: average 78), to whether instructors have sufficient experience and training (Instructor factors; Q41_1: average 62), to whether instructors have access to sufficient professional development (Q41_2: average 55). Taken from a high level, if any average above 50 is considered confirmation of a positive level of confidence in the course, then the data suggest that confidence in the MMPW course across the three factors is positive.

The average level of confidence is not equal, however, across all aspects of the course. There is almost a 30-point difference between the highest rated average level of confidence (whether students who have taken an MMPW course are readier to write in the workplace than 
students who have not taken the MMPW course [Q38_3; average 84]) and the lowest rated average level of confidence (whether instructors have access to sufficient professional development [Q41_2: average 55]). Another lower rated average level of confidence appears for whether sections of the MMPW are equal in rigor and presentation of standard curriculum (Q41_1; average 59). Even though the level of confidence in the course among respondents is on average at positive levels, the confidence levels vary depending on the aspect of the course under consideration.

\section{Respondents Reported Lower Confidence in Instructor Factors Than Student}

\section{Factors}

The average levels of confidence across all prompts for a given factor (student, instructor, institutional) make visible the variation in confidence levels by aspect of the course (see Table 10). The average slider response across all prompts related to students (student factors) is higher, on average, than confidence in aspects of the course that are related to instructors or institutions (instructor and institutional factors). Although average confidence levels in instructor and institutional factors are about the same (61 and 64, respectively), average confidence levels in student factors are notably higher (77).

\section{INSERT TABLE 10 HERE}

What the overall positive levels of the averages in Table 10 do not account for, however, are the extent to which the responses that were below 50 (sort of confident) across all of the slider prompts affect the overall averages. As we considered the data, we found ourselves 
wondering what confidence levels across all three factors would look like if we broke out the responses of the $19.4 \%$ of respondents who registered a less than 50 response to question Q62 (overall confidence in the effectiveness of the MMPW course): How would the trend in lower confidence in instructor factors than student factors look within this less confident group? New insights emerged into the variation in average confidence levels between student, instructor, and institutional factors (see Table 11) when the data was sorted into whether respondents recorded an overall confidence level (Q62) of either above 50 or below 50.

\section{INSERT TABLE 11 HERE}

Breaking out the respondents who recorded less than 50 for overall confidence level confirmed the trend of lower levels of confidence in instructor factors than student factors. Most notably, the disparity between the average level of confidence in student factors (60) and the average level of confidence in instructor factors (32) - a disparity of almost 30 points - is even more pronounced for the less-than-50 group than for respondents overall (difference of 16 points between student and instructor factors). In addition, this level of disparity is maintained across all three survey questions that relate to instructors: whether instructors have sufficient experience and training (Q41_1; average 31); whether sections are equal in rigor and presentation of standard curriculum (Q41_4; average 32); and whether instructors have access to sufficient professional development (Q41_2; average 34). Although the average levels of confidence in instructor factors are lower than student factors across all respondents, this trend is even more pronounced for the $19.4 \%$ of respondents who recorded an overall lower level of confidence in the course. We take this trend as confirmation that an important source of lower confidence for 
the less-than-50 group is in aspects of the MMPW course that relate to instructor experience, training, and effectiveness. Looking across all of the average levels of confidence in student, instructor, and institutional factors, broken out by overall confidence level in the course (see Table 12), the average level of confidence for instructor factors (32) for the less-than-50 group stands out as the lowest level of confidence overall.

INSERT TABLE 12 HERE

Lower Confidence in Instructor Factors is Not Related to Institutional Type or Instructor Rank

Having noticed the trend across all respondents in the lower level of confidence in aspects of the course that relate to instructor experience, training, and effectiveness, we wondered whether respondents with a specific instructor rank or institutional type were represented more heavily than others in the lower confidence group. Since $56 \%$ of respondents indicated that most of the MMPW course sections at their institution are taught by nontenure-track faculty (28\% part-time adjunct; $27 \%$ full-time nontenure-track; $6 \%$ graduate TA) and the most frequent institutional type where most MMPW courses are taught by adjunct faculty was associate's (56\%), we wondered whether respondents off the tenure track with institutional type of associate's would be represented at a higher frequency in the less-than-50 group than in respondents as a whole. This assumption would seem warranted given that, broadly speaking, instructors off the tenure track often have higher teaching loads yet less access to professional development then tenure-track colleagues, especially at institutions with fewer resources. 
Notably, this assumption turned out to be wrong (see Table 13). When we took into consideration the institutional type and instructor rank of the lower confidence group (under 50 on Q62) we found that both indicators were in range of being proportionately represented at the same rate as among survey respondents as a whole. For example, percentage representation of institutional affiliation at associate's colleges was very similar between the under-50 group (40\%) and respondents as a whole (38\%). Likewise, $20 \%$ of both the under-50 group and respondents overall claimed adjunct/part-time as their instructor rank. The other categories were also similar, except for a moderate divergence between the representation of the instructor rank of tenure track in the under-50 group (47\%) and respondents as a whole (38\%). Overall, comparing the representation of institutional type and instructor rank between the group with overall lowest confidence in the MMPW course and survey respondents as a whole did not reveal any meaningful trends that might suggest that either one of these factors contributes more strongly than anything else to a lower level of confidence in the course.

INSERT TABLE 13 HERE

Individual Cases of Respondents with the Lowest Confidence Levels Look

\section{Unique}

Given that there was no clear trend linking institutional status and instructor rank to a lower level of confidence in the course overall, we turned to looking at other aspects of the individual situations of the ten respondents with the lowest overall confidence levels (under-40 for Q62) to see if we could find any patterns in their situations. Among these ten respondents, we looked at primary area of graduate training, number of MMPW sections taught per year at that institution 
(1-10, 11-50, more than 50), faculty rank of who teaches the most sections (TT, FT NTT, PT/adjunct, TA), presence of a course coordinator (yes/no), presence of a common syllabus for the course (yes/no), and access to professional development (yes/no). Notably, even among this least confident group, we found that most combinations of answers to these questions were present across all institutional types and faculty ranks. In other words, when considered at an individual level, respondent situations look unique.

Given that the situations of the ten respondents with the lowest of confidence in the course look unique, it would be possible to conclude that the overall confidence levels of these respondents are not linked to any of the elements measured by the survey, but to other things entirely (which could easily be the case). It would also be possible to conclude that the institutional situations and instructor profiles for survey respondents vary so much that each case can only be considered on its own terms. These are both reasonable conclusions to draw from these ten respondent cases; however, we do not want this ambivalence to overwhelm what we understand as a robust and meaningful trend in the subjective assessment data from this survey: that a lower level of confidence in the instructor factors related to the course (compared to confidence in the value the course has for students) is generalized in the data across all institutional types, instructor ranks, and institutional situations. In addition, though the lower level of confidence in instructor factors is more pronounced for the $19.4 \%$ of respondents who reported a lower level of confidence in the course overall, it is also true, on average, that across all survey respondents there is a lower level of confidence in the instructor corps for the MMPW course than in the confidence level for the value that it has for students. We understand this to mean that a meaningful number of MMPW course instructors across all institutional types and 
instructor ranks feel that the MMPW instructor corps at their institution is lacking in experience, training, and access to professional development.

\section{What Do We Know about the MMPW Instructor Corps That Can Explain This}

\section{Lower Confidence?}

Given the generalized sentiment that the instructor corps for the MMPW course is lacking in experience, training, and access to professional development, we turned to the descriptive data from survey respondents about levels of training, experience in industry, and access to professional development to see if there were any strong trends that might explain this sentiment.

Table 14 displays the frequency of responses for aspects of instructor training by institutional type, including highest degree obtained $(\mathrm{PhD}$ or MA/MFA/MX — any other type of master's degree), graduate training specifically in professional and technical communication (PTC) or composition or writing studies (Comp.), PTC experience in industry, and access to professional development opportunities at the home institution. In our discussion we will focus on the data from doctoral and associate's institutions because the number of respondents in each of those groups is roughly equal ( $N=58$ and 60 , respectively) and together these two institutional types comprise a large proportion of institutions of higher education overall (68\%, Carnegie 2015 data).

INSERT TABLE 14 HERE 
Given this relative comparability between these two groups, Table 15 suggests trends in instructor training, experience, and access to professional development that are on the one hand anticipated and at the same time troubling.

\section{INSERT TABLE 15 HERE}

Although the frequency of PhD as the highest degree earned by MMPW instructors is higher at doctoral institutions (59\%) than at associate's institutions $(33 \%)$, we did not find this to be unexpected, given that historically a $\mathrm{PhD}$ has not been a minimum requirement for full-time (tenure-track and nontenure-track) positions at two-year colleges. Nor did we find it unexpected that the frequency of master's degrees (of any type) is in roughly equal inverse proportion to PhDs across both institutional types (31\% doctorate; 52\% associate's). However, when the primary focus of graduate training is taken into account, a stronger trend is noticeable. When asked to declare the primary focus of their graduate training, only $3 \%$ of respondents at associate's colleges chose professional or technical communication (PTC) compared to $28 \%$ at doctorate-granting institutions. Since we don't want to suggest that only graduate training specific to PTC qualifies an instructor to teach the MMPW course, we also took into consideration the frequency with which respondents declared composition (Comp.) as an area of graduate training. When the frequencies of graduate training in PTC and Comp. are aggregated, the disparity between doctorate-granting and associate's institutions widens significantly: $72 \%$ of respondents from doctorate-granting institutions have graduate training in either PTC or Comp., whereas this is only the case for $35 \%$ of respondents at associate's institutions - a disparity of 37 points. We find this disparity to be meaningful, especially in light of the fact that these 
frequencies mean that $65 \%$ of respondents at associate's colleges (and $28 \%$ at doctoral institutions) do not have graduate training in writing studies related fields. This trend suggests that a source of the lower level of confidence in the MMPW instructor corps is relevant graduate training (or lack thereof).

Notably, when it comes to experience in industry with professional and technical communication, respondents at both institutional types responded with similar frequency $(60 \%$ at doctoral; $57 \%$ associate's). Respondents who answered affirmatively to having relevant experience in industry were also asked to describe that experience. In these write-in answers respondents described a full range of experiences that would be considered relevant industry experience for teaching the MMPW course: working as a professional in industries such as banking, nonprofits, construction, information technology, human resources; working as an executive secretary; being employed as a technical writer or technical editor or doing this work as an independent contractor; having careers in journalism, publishing, and other media industries.

Although we found the relatively high (compared to graduate education) frequency of industry experience among respondents to be good news overall, we do want to raise the point that one of the differences between experience in industry and graduate training in PTC or composition is the exposure to writing pedagogy and rhetorical studies. Certainly, an MMPW instructor with industry experience who is able to speak with authority about encountering writing situations in real workplaces has an edge over an instructor who has never encountered such writing situations. However, this edge is limited by the instructor's access to and openness 
to learning the best practices for teaching writing and the rhetorical thinking that is at the foundation of teaching for learning transformation (see, for example, Brent, 2012). Although industry experience is valuable, it is neither sufficient nor a substitute for either graduate training or other formal training in writing pedagogy (see also Meloncon \& England, 2011, for a discussion of hiring working professionals to teach TPC). As a result, a source of lower confidence in the MMPW course instructor corps could be that respondents recognize a lack in instructor training, despite a relatively high number of instructors with industry experience.

In terms of access to professional development, respondents at associate's and doctoral institutions reported having access at fairly similar rates (55\% and 64\%, respectively). Although more respondents from doctoral institutions reported having access to professional development than respondents at associate's institutions, the difference ( 9 points) is neither notable nor unexpected given historic trends in how institutions are funded and the fact that institutional investment in instructor development varies significantly by instructor rank (TT vs. adjunct, for example). Given this ambivalence, we are left with the interpretive choice of reading these frequencies as either positive (over half of respondents in both categories have access to professional development) or as negative (nearly half of respondents at associate's institutions do not have access to professional development). In both cases, the survey does not provide the data or the warrant for making more than an arbitrary choice to read the data one way or the other. Either way, the interpretive choice depends on whether these frequencies exceed our individual expectations, or not, and how we see the rates of access to professional development changing over time (either increasing or decreasing). The ambivalence in the analysis of this data about 
professional development, however, should not prevent it from warranting arguments for greater investment in the professional development for MMPW instructors.

In sum, we argue that our data shows that across all respondents there is an overall positive level of confidence in the MMPW course. This is especially true when it comes to the confidence that MMPW instructors have that students benefit from taking this course. However, we argue that there is a meaningfully lower level of confidence in the training and experience of the instructor corps who teach the MMPW course that warrants attention from institutions and the field.

\section{What Would Improve MMPW Instructor Confidence in the}

\section{Course?}

Our intention in designing and executing this survey research has always been to provide the field with a resource for discussing how the status of the MMPW course can be improved. As much as we wanted to create a snapshot in time of how this course is institutionally situated, the curricular and pedagogical norms for the course, who teaches the course, and how confident instructors are in the course, we also wanted to capture data that would point to interventions for improving the status of the course within individual institutions and, more generally, across the fields of professional and technical communication and writing studies.

In this spirit, our survey ended with an exercise that prompted respondents to sort items that might improve their confidence in the MMPW course at their institution into boxes labeled: would definitely help; would help a little; would make no difference; already doing; and not 
relevant. Items that might improve confidence in the course included items related to instructor training and experience, items related to changes in the institutional situation of the course, and items related to the pedagogy and instructional materials for the course.

To simplify the presentation of the data and to make positive trends clearer, we created a category called "would help" that aggregates both the "would definitely help" and the "would help a little" responses for each item. We then ranked the items based on the cumulative total of the new "would help" category (see Table 15). Table 15 also includes the number of "would make no difference" and "already doing" responses for each item. As would be expected, as the number of "would help" responses diminish, the number of "would make no difference" and "already doing" responses rises.

This data has value as a snapshot of what kinds of interventions would improve the confidence of instructors in the MMPW course. There are several notable trends to which we would like to draw attention. First, we find it notable that the top three ranked items are all directly related to instructor experience and training: (1) Training in contemporary workplace technologies for instructors; (2) More instructors with industry experience; tied with (2) More instructors with a scholarly interest in professional writing. This trend supports the findings in the previous section about the lower level of confidence in instructor factors over student factors and the low levels of instructor training in TPC and composition, in particular at associate's institutions. From our results we can say with confidence that as a group, MMPW course instructors and coordinators have a lower level of confidence in the training and experience of 
the instructor corps and that as a group the most frequently chosen items that "would help" increase confidence in the course are related to instructor experience and training.

Additionally, we note that the next four most frequently chosen items that "would help" are ones that are related to curricular matters, either directly or indirectly. The number four ranked item - adding an experiential dimension to the course (internship, service learning, or client project) - is an acknowledgement of the now widely held view that connecting students with real workplace writing situations is a pedagogical best practice for the MMPW course. Smaller class sizes (5), a longer course sequence (6), and additional classroom technologies (7) address curricular matters more indirectly, yet also point to ways to enhance the curriculum: Smaller class sizes make experiential learning more possible; a longer course sequence creates room for additional content in the course, and additional classroom technologies expand the modes of learning and skill sets that students can learn in the course.

Interestingly, the items that relate to the institutional situation of the course are ranked at the bottom half of the list. This finding speaks to the fact that items such as the existence of standardized outcomes (8), resources to assess the course (9), and the presence of a course coordinator (11) have among the highest level of "already doing" responses $(42,37$, and 54 , respectively). We were surprised that we didn't find stronger negative trends in the institutional situation for the course. For example, $78 \%$ of respondents reported the existence of a common set of outcomes for the MMPW course at their institutions; almost half of respondents reported a MMPW course coordinator (46\%); and 58\% of respondents reported that an assessment process for the course was in place. Aside from the definitely positive frequency of course outcomes, 
however, we remain unsure whether to interpret the respondent frequencies for a course coordinator and assessment process as positive or negative. Does it call out a deficit in the institutional situation of the course that around half of survey respondents reported no MMPW course coordinator and no resources for assessing the course? This number is certainly tempered by variations in the institutional situations of the course, such as the fact that $49 \%$ of respondents reported that 10 or fewer sections of the course were taught each year, in which case a course coordinator may not be necessary. Or is the inverse true, that for a course that has often existed at the periphery of English departments these frequencies are heartening and indicative of a positive trend in the development of the MMPW course? Without data that reflects these trends over time it is hard to tell which story is more reflective of the status of the course in the field as a whole.

\section{CONCLUSION}

This article began with a fairly typical course description for the MMPW course. By calling attention to what, for so many stakeholders, is hidden in plain sight (i.e., the normalization of the course in U.S. higher education), our purpose in conducting our survey was to investigate the status of the MMPW course across its diverse institutional contexts - to ask, essentially, "What is going on right now with this course?".

Our survey findings lead us to suggest that there is systemic underinvestment in the MMPW course by postsecondary institutions across all institutional types. This underinvestment has consequences that have shown up in our findings, such as the persistence of formalist, genrebased pedagogical and curricular norms that are reified in the most commonly used standard 
textbooks. Another consequence is that, though instructors have a high level of confidence in the value that the MMPW course has for students, they have a lower level of confidence in the instructor corps that teach the course. These findings point to underinvestment by institutions in hiring instructors with the proper qualifications to teach the course as well as underinvestment in professional development opportunities to keep instructors current in their knowledge of the field. Unsurprisingly, given this underinvestment, the most frequently chosen item for increasing confidence in the MMPW course was related to instructor training and preparedness. This finding points to an urgency to improve instructor development and strengthen hiring practices.

Our argument about underinvestment in the MMPW course is motivated by what we see as an urgency to initiate a conversation to promote change that is past due. The first step toward the conversation we are suggesting is to view the MMPW course as a shared phenomenon across institutional contexts that can be taken up by the professional bodies that serve these constituencies. One place the professional organizations with a stake in this course (e.g., NCTE/CCCC, CWPA, ATTW, CPTSC, ABC) can begin is in the development of a shared set of standardized outcomes similar to those the Council of Writing Program Administrators has produced and continues to update for first-year composition (FYC). Although there are limits to the comparisons one can make between the MMPW course and the FYC course, the ubiquity of and nearly universally professed value in the MMPW course surely merits a similar level of attention and investment by our professional organizations.

We anticipate that such a conversation will not be easy. Few have a stake in arguing against the current status of the MMPW course: students see it as a necessity for career 
preparation, humanities faculty see it as a gesture toward professional training in a curricular environment that is increasingly hostile to the liberal arts, professional schools are satisfied that once their students complete an MMPW course they have had adequate exposure to training in communication skills, contingent faculty see the MMPW course as a predictable source of income, the textbook industry sees the course as a cash cow, and department and college administrators rely on MMPW course enrollments as a key source of revenue. But we argue that we, as a profession, can and should hold ourselves to a higher standard for the MMPW course.

\section{NOTES}

1. This number is an estimate based on the number of each Carnegie type institutions (doctoral, master's, baccalaureate, associate's; 2015 numbers) and the frequency with which survey respondents reported the number of sections of the MMPW course taught each year at their institution $(1-10 ; 11-50 ;>50)$. To be conservative, calculations used the middle number in the lower ranges (5 and 30) and the lowest number (51) for the "more than 50" category. The unrounded estimated total for the overall number of sections of the MMPW course taught each year is 43,538 .

2. This number is based on the National Census of Writing conducted by Swarthmore (20132014) finding that $81 \%$ of the schools in the census reported that they require first-year composition. Because a large majority of students (86\%) are enrolled at institutional types that are also the most common locations for the FYC course (doctoral, master's and associate's institutions), we did not break this calculation down by institutional type since the order of magnitude of the total number would not have changed. In addition, we did not account for the 
percentage of students who place out of the course because of grades or testing (such as AP testing) or first year student retention rates. We assumed that there are an estimated 5 million college first year students (one quarter of the total number of college students for 2015 as reported by Carnegie) and we assumed an average of 20 students per section. Given these assumptions, the unrounded estimated total number of sections is 202,500 . We assume that this number has meaning only to the order of magnitude of the closest ten thousand.

3. The coffee cards were delivered electronically, thus preserving the de-identification of the survey data.

\section{FUNDING}

This research was supported by a Research Initiative Grant from the Conference on College Composition and Communication.

\section{ACKNOWLEDGEMENTS}

The authors would like to thank the National Council of Teachers of English and the Conference on College Composition and Communication for funding our study with a Research Initiative Grant. We would also like to thank Jessica Bishop-Royse at the Social Science Research Center at DePaul University for her support with survey methods and our summer research assistant, Theresa Bailey, for her work with recruitment and transcription. Additionally, we would like to thank Amy Hornat-Kaval, Rosemary Golini, and Joseph Szpila for helping us user test the survey. Finally, we would like to thank all of the survey respondents for their generosity of their 
time and willingness to share and the anonymous $T C Q$ reviewers for helping to strengthen our manuscript.

\section{NOTES ON CONTRIBUTORS}

Sarah Read is assistant professor of English and Director of Technical and Professional Writing at Portland State University in Portland, Oregon. Her work has appeared in Technical Communication Quarterly, Journal of Business and Technical Communication, College Composition and Communication, and Journal of Writing Research.

Michael J. Michaud is associate professor of English at Rhode Island College in Providence, Rhode Island. His work has appeared in College Composition and Communication, Writing and Pedagogy, and Writing on the Edge.

\section{REFERENCES}

Allen, N., \& Benninghoff, S. T. (2004). TPC program snapshots: Developing curricula and addressing challenges. Technical Communication Quarterly, 13(2), 157-185. doi:10.1207/s15427625tcq1302_3

Banerjee, A., \& Chaudhury, S. (2010). Statistics without tears: Populations and samples. Industrial Psychiatry Journal, 19(1), 60-65. doi:10.4103/0972-6748.77642

Blakeslee, A. M. (2001). Bridging the workplace and the academy: Teaching professional genres through classroom-workplace collaborations. Technical Communication Quarterly, 10(2), 169192. doi:10.1207/s15427625tcq1002_4

Brent, D. (2012). Crossing boundaries: Co-op students relearning to write. College Composition and Communication, 63(4), 558-92.

Carnegie Classification of Institutions of Higher Education, Center for Postsecondary Research. (2016a). 2015 Update: Facts \& Figures. Bloomington, IN: Indiana School of Education. 
Carnegie Classification of Institutions of Higher Education, Center for Postsecondary Research. (2016b). Standard Listings. Retrieved from http://classifications.carnegiefoundation.org

Connors, R. J. (1982). The rise of technical writing instruction in America. Journal of Technical Writing and Communication, 12(4), 329-53.

Crowley, S. (1998). Composition in the university: Historical and polemical essays. Pittsburgh, PA: University of Pittsburgh Press.

Curtis, J. W. (2014). The employment status of instructional staff members in higher education. Washington, DC: American Association of University Professors.

Dayton, D., \& Bernhardt, S. A. (2004). Results of a survey of ATTW members, 2003. Technical Communication Quarterly, 13(1), 13-43. doi:10.1207/S15427625TCQ1301_5

Johnson-Sheehan, R. (2014). Technical communication strategies for today (2nd ed.). Upper Saddle River, NJ: Pearson.

Kain, D., \& Wardle, E. (2005). Building context: Using activity theory to teach about genre in multi-major professional communication courses. Technical Communication Quarterly, 14(2), 113-39. doi:10.1207/s15427625tcq1402_1

Kelley, K., Clark, B., Brown, V., \& Sitzia, J. (2003). Good practice in the conduct and reporting of survey research. International Journal for Quality in Health Care, 15( 3), 261-66. doi:10.1093/intqhe/mzg031

Kolin, P. (2012). Successful writing at work (10th ed.). Boston, MA: Cengage.

Lannon, J. (2007). Technical communication (11th ed.). New York, NY: Longman. 
Lannon, J., \& Gurak, L. J. (2016). Strategies for technical communication in the workplace (3rd ed.). New York, NY: Pearson.

Lehman, C. M., \& DuFrene, D. D. (2010). Business communication (16th ed.). Mason, OH: South-western Cengage Learning.

Markel, M. (2014). Technical communication (11th ed.). New York, NY: Bedford/St. Martin's.

McKenna, B., \& Thomas, G. (1997). A survey of recent technical writing textbooks. Journal of Technical Writing and Communication, 27(4), 441-452. doi:10.2190/CGA9-CVJY-82CX-AEFJ

Meloncon, L. (2012). Current overview of academic certificates in technical and professional communication in the United States. Technical Communication, 59(3), 207-222.

Meloncon, L., \& England, P. (2011). The current status of contingent faculty in technical and professional communication. College English, 73(4), 396-408.

Meloncon, L., \& Henschel, S. (2013). Current state of US undergraduate degree programs in technical and professional communication. Technical Communication, 60(1), 45-64.

National Census of Writing. (2013). How would you describe your first-year writing requirement? Retrieved from http://writingcensus.swarthmore.edu

Oliu, W. E., Brusaw, C. T., \& Alred, G. J. (2016). Writing that works: Communicating effectively on the job (12th ed.). New York, NY: Bedford/St. Martin's.

Read, S., \& Michaud, M. (2015). Writing about writing and the multimajor professional writing course. College Composition and Communication, 66(3), 427-457. 
Reave, L. (2004). Technical communication instruction in engineering schools a survey of topranked US and Canadian programs. Journal of Business and Technical Communication, 18(4), 452-490. doi:10.1177/1050651904267068

Searles, G. J. (2013). Workplace communication: The basics (6th ed.). New York, NY: Pearson.

Spinuzzi, C. (1996). Pseudotransactionality, activity theory, and professional writing instruction. Technical Communication Quarterly, 5(3), 295-308. doi:10.1207/s15427625tcq0503_3

Staples, K. (1999). Technical communication from 1950-1998: Where are we now? Technical Communication Quarterly, 8(2), 153-164. doi:10.1080/10572259909364656

Sullivan, P. A., \& Porter, J. E. (1993). Remapping curricular geography: Professional writing in/and English. Journal of Business and Technical Communication, 7(4), 389-422. doi:10.1177/1050651993007004001

Tate, G., Tagart, A. R., Schick, K., \& Hessler, H. B. (2013). A guide to composition pedagogies (2nd ed.). New York, NY: Oxford University Press.

Tebeaux, E., \& Dragga, S. (2014). The essentials of technical communication (3rd ed.). Oxford, UK: Oxford University Press.

Warren, T. L. (1996). An informal survey of technical writing textbooks: 1950-1970. Journal of Technical Writing and Communication, 26(2), 155-161. doi:10.2190/1QD8-PK64-X0RJ-ATWG Wickliff, G. A. (1997). Assessing the value of client-based group projects in an introductory technical communication course. Journal of Business and Technical Communication, 11(2), 170-191. doi:10.1177/1050651997011002002 
Yeats, D., \& Thompson, I. (2010). Mapping technical and professional communication: A summary and survey of academic locations for programs. Technical Communication Quarterly, 19(3), 225-261. doi:10.1080/10572252.2010.481538

Author Bios

Sarah Read is assistant professor of English and Director of Technical and Professional Writing at Portland State University in Portland, Oregon. Her work has appeared in Technical Communication Quarterly, Journal of Business and Technical Communication, College Composition and Communication and Journal of Writing Research.

Michael J. Michaud is associate professor of English at Rhode Island College in Providence, Rhode Island. His work has appeared in College Composition and Communication, Writing and Pedagogy, and Writing on the Edge.

\section{Appendix}

\section{Institutional Situation}

1. What is your current or recent association with a MMPW Course? Check all that apply.

2. At how many institutions do you currently teach or coordinate a MMPW course?

3. Choose the type of institution where you PRIMARILY teach or coordinate with the MMPW course (choose one only).

4. Please write in the course number and title of the MMPW course that you teach or coordinate. (Example: English 234: Introduction to Professional Writing) 
5. If available, please copy and paste the catalog description for the MMPW course you teach or coordinate:

6. In what department, program, or college is the MMPW course offered?

7. About how many sections of this course are offered each year?

8. Is there a program administrator or coordinator for the MMPW course?

\section{Curricular Situation}

1. Are there prerequisites for the MMPW course at your institution, other than the first-year writing sequence in writing?

2. Which of the following function as prerequisites for the MMPW course at your institution? (select all that apply)

3. Is the MMPW course at your institution a stand-alone or part of a larger instructional sequence?

4. If the MMPW course is a part of a larger instructional sequence, which of the following best characterizes the kind of sequence it's a part of?

5. What types of students take this course? (check all that apply)

6. To the best of your knowledge, which of the following groups of students are REQUIRED to take the MMPW course? (select all that apply) 
7. To the best of your knowledge, which of the following groups of students occasionally CHOOSE to take the MMPW course, even though they may not be required to do so? (select all that apply)

\section{Faculty}

1. Which types of faculty members teach MMPW at your institution? (please check all that apply):

2. Which type of faculty member teaches THE MOST sections of MMPW courses at your institution? (choose one):

3. What is your institutional/instructional status?

4. What is your highest degree obtained?

5. What is your primary field of graduate training?

6. Beyond teaching MMPW courses, is professional/technical writing a scholarly area of interest for you?

7. If no, what would you consider your PRIMARY area of interest for scholarly research or writing?

8. If yes, briefly describe a recent or current interest or project.

9. Do you bring relevant industry or other nonacademic experience to the teaching of professional writing? 
10. If yes, please describe that experience.

11. How many years of experience do you have teaching ANY kind of writing?

12. How many years of experience do you have teaching the MMPW course?

\section{Curriculum and Instruction: Course Materials}

1. Do you or have you used a textbook to teach the MMPW course?

2. Which of the following is the textbook that you use NOW or have used most recently?

3. Why did you choose this textbook?

4. What other course materials do you use? Check all that apply:

\section{Curriculum and Instruction: Section Standardization}

1. Do all sections of the MMPW course at your institution share a common syllabus?

2. Is there a standardized set of course outcomes for MMPW instruction at your institution?

3. Do instructors write their own MMPW course outcomes?

4. Is there a college, department, or program process for assessing the success of MMPW sections meeting these outcomes? 


\section{Curriculum and Instruction: Pedagogy}

1. Which of the following approaches characterize how you teach your MMPW course? (choose all that apply)

2. Now choose only your CENTRAL or PRIMARY approach for teaching the MMPW course? (choose one)

\section{Curriculum and Instruction: Technology}

1. Have you recently taught the MMPW course in a computer lab?

2. Have you recently taught an online or hybrid version of the MMPW course?

\section{Curriculum and Instruction: Professional Development}

1. Do have access to professional development opportunities for faculty who teach this MMPW course?

2. Have you, personally, ever pursued professional development opportunities to improve your MMPW instruction?

3. Do you enjoy teaching and/or coordinating the MMPW course?

4. Please tell us why you feel this way:

\section{Subjective Assessment}


Slide the pointer to reflect your level of confidence as prompted by the question in the left-hand column.

1. Overall, how confident are you in the effectiveness of the MMPW course at your institution?

2. Students feel more ready to write in workplace contexts after taking the MMPW course.

3. The MMPW course helps students to acquire sufficient and appropriate technological skills to write in future workplace contexts.

4. MMPW students are more ready to write in the workplace than students who have not taken the MMPW course.

5. MMPW instructors at your institution have sufficient experience and training in professional writing to effectively teach this course.

6. MMPW instructors at your institution have sufficient access to professional development, including training in contemporary technologies, to effectively teach the MMPW course.

7. MMPW instructors at your institution have access to sufficient technologies in the classroom to effectively teach the course.

8. Sections of the MMPW course at your institution are equal in terms of rigor and the presentation of standard curriculum. 
What would help to IMPROVE your confidence in the MMPW course at your institution? Please drag and drop from the list of "Items" on the left to the appropriate boxes on the right.

1. Adding an experiential dimension to the course (internship, service learning, or client project).

2. Additional classroom technologies, including software and hardware.

3. A set of standardized outcomes for the course from a professional organization such as WPA, ATTW, CPTSC, or other.

4. Training in contemporary workplace technologies for instructors.

5. Smaller class sizes.

6. New textbooks that support contemporary workplace writing practices.

7. A longer MMPW course sequence (2 or more quarters or semesters).

8. More instructors with industry experience.

9. More instructors with a scholarly interest in professional writing.

10. A college-, department-, or program-level coordinator for the MMPW course.

11. Changing the department location of the course (from Business to English, for example, or vice versa). 
12. Resources to assess the course across sections on a regular basis.

13. More sections of the course (larger course enrollments). 
Table 1. Percentage of Survey Respondents by Carnegie Classification Institution

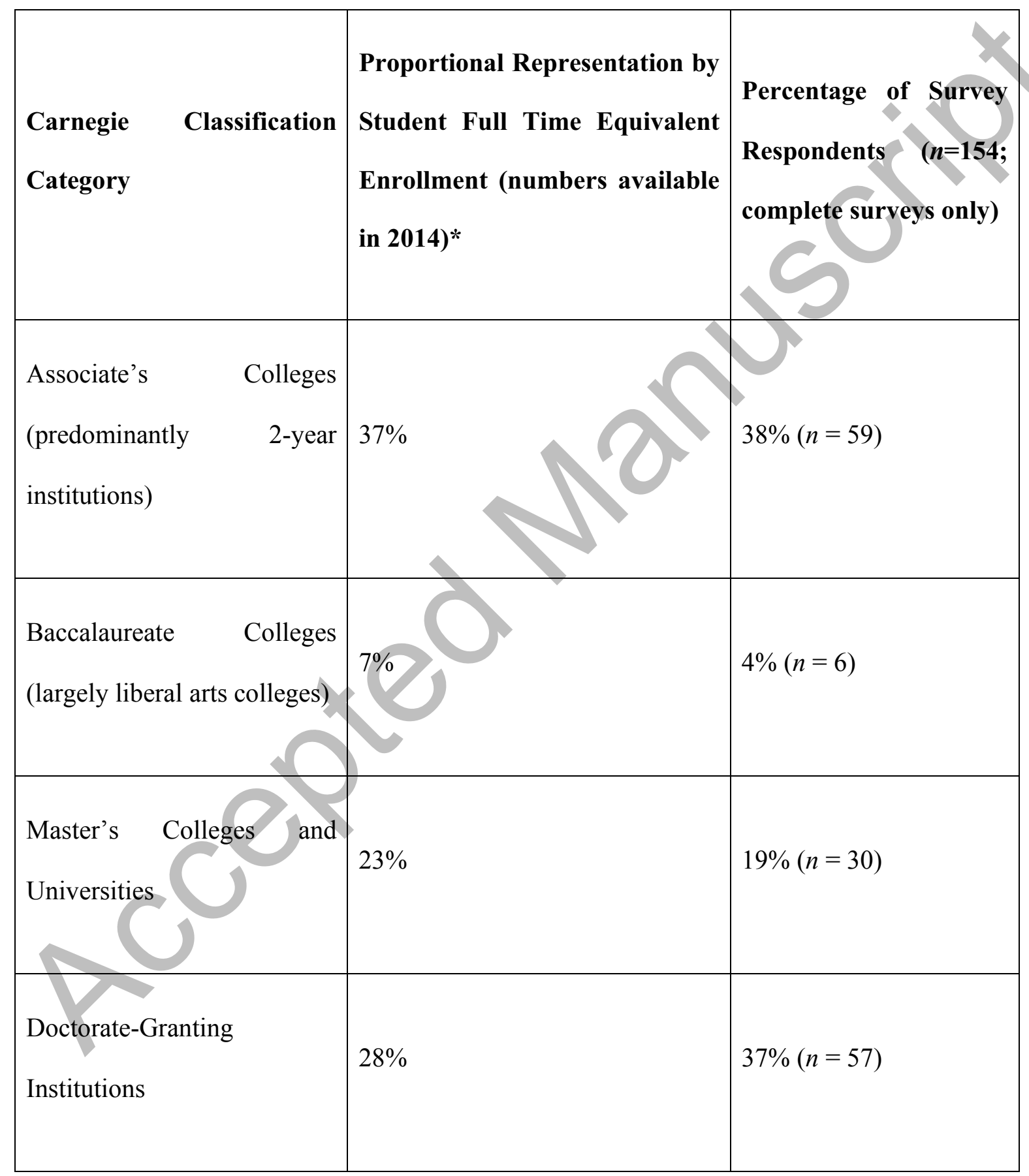




\begin{tabular}{|l|l|l|}
\hline Special Focus \& Faith & & \\
Institutions (includes stand- & $7 \%$ & $1 \%(n=1)$ \\
alone law, business, and & & \\
medical schools) & $1 \%$ & $1 \%(n=1)$ \\
\hline Tribal Colleges & & \\
\hline
\end{tabular}

*Numbers rounded up to nearest whole number. Total exceeds $100 \%$ because of rounding. 
Table 2. Percentage of Survey Respondents by Faculty Rank

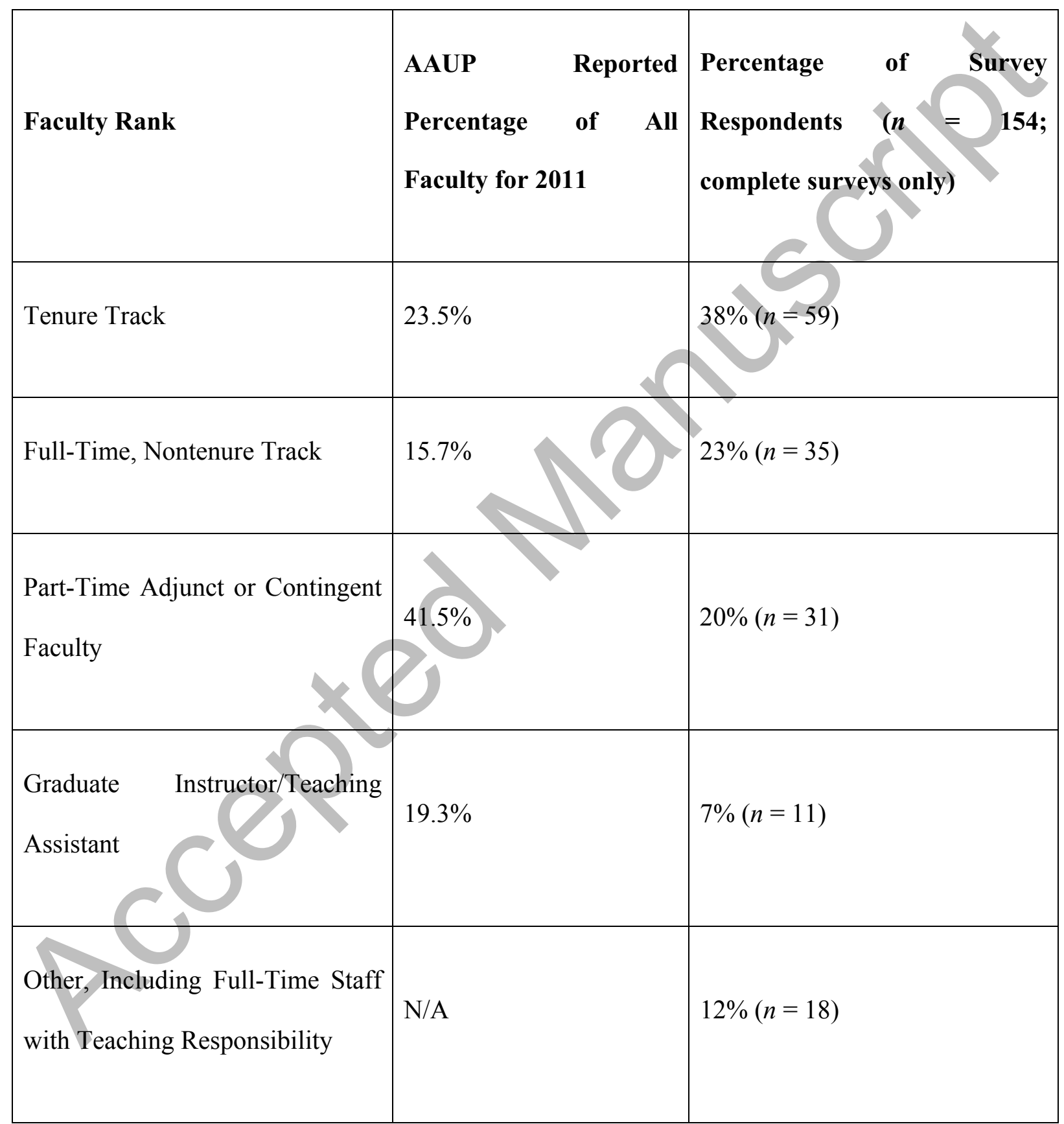


Table 3. Results for Q6: Do you or have you used a textbook to teach the MMPW course?

\begin{tabular}{|l|l|l|l|}
\hline Institutional Type & Yes & No & Percentage Yes \\
\hline Associate's College & 56 & 3 & $95 \%$ \\
\hline Baccalaureate College & 4 & 2 & $67 \%$ \\
\hline Master's College or University & 27 & 3 & $90 \%$ \\
\hline Dribal College & & & \\
\hline Special Focus or Faith & 53 & 4 & $93 \%$ \\
\hline & 1 & 0 & $100 \%$ \\
\hline
\end{tabular}


Table 4. Results for Q76: Why did you choose this textbook?

\begin{tabular}{|l|l|l|}
\hline Answer Choice & Responses & Percentage of Textbook \\
\hline It is required by the program/department & 32 & Users $(n=142)$ \\
that all sections of this course use this & & $23 \%$ \\
textbook & & \\
\hline I personally chose it & 88 & $62 \%$ \\
\hline Total & 22 & $100 \%$ \\
\hline
\end{tabular}


Table 5. Results for Q76: Why did you choose this textbook?

\begin{tabular}{|c|c|c|c|}
\hline Institutional Type & $\begin{array}{l}\text { It Is Required by the } \\
\text { Program or Department } \\
\text { That All Sections of } \\
\text { This Course Use This } \\
\text { Textbook }\end{array}$ & $\begin{array}{l}\text { I Personally } \\
\text { Chose It }\end{array}$ & $\begin{array}{l}\text { Percentage } \\
\text { Chose Own } \\
\text { Textbook }\end{array}$ \\
\hline Associate's College & 19 & 28 & $60 \%$ \\
\hline Baccalaureate College & & 4 & $100 \%$ \\
\hline Master's Colle & 3 & 20 & $87 \%$ \\
\hline Doc & 10 & 35 & $78 \%$ \\
\hline Special Focus or Faith & 0 & 1 & $100 \%$ \\
\hline Tribal College & 0 & 0 & $\mathrm{~N} / \mathrm{A}$ \\
\hline
\end{tabular}


Table 6. Results for Q84: Which of the following is the textbook that you use NOW or have used most recently?

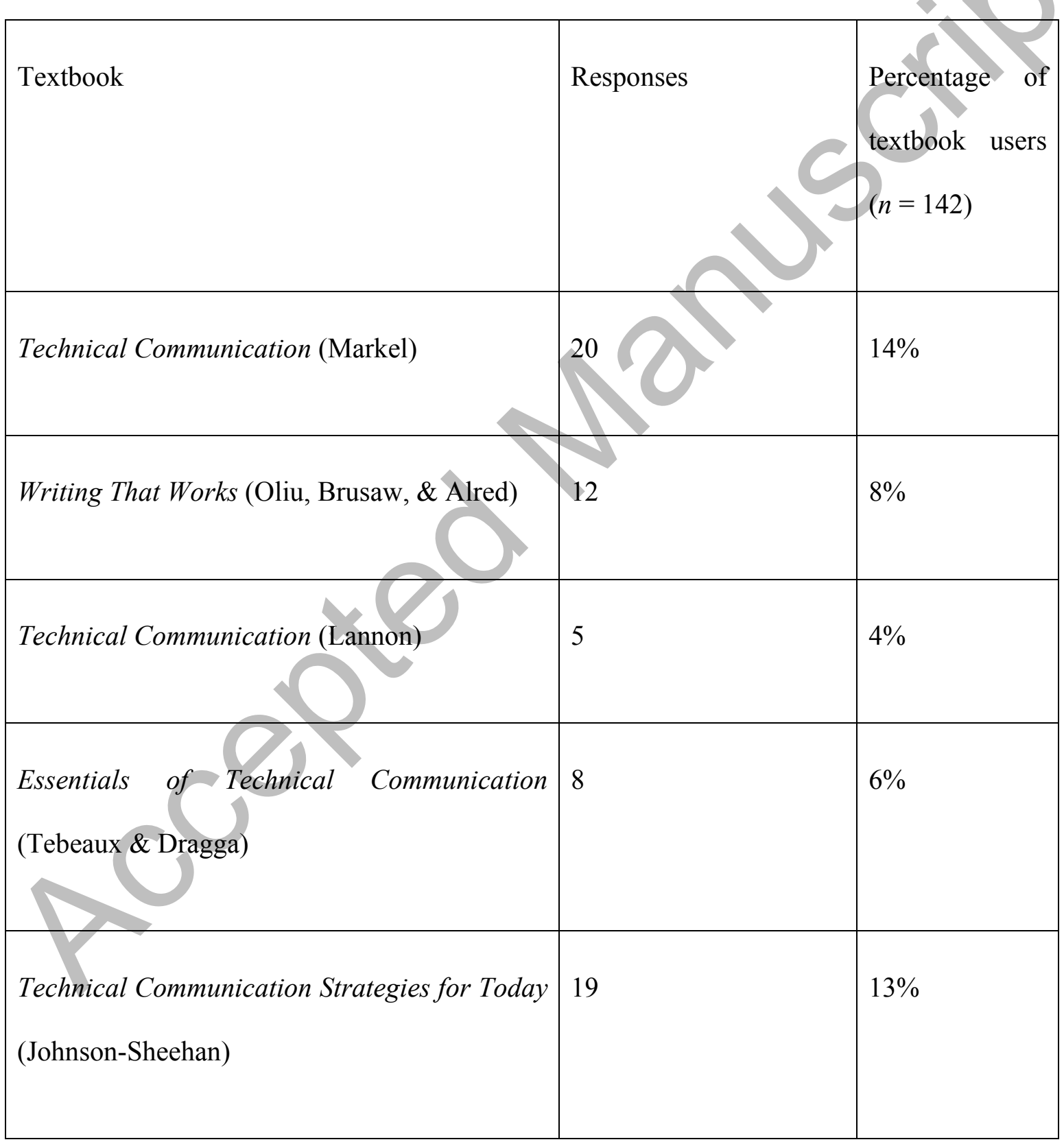




\begin{tabular}{|l|l|l|}
\hline Strategies for Technical Communication & 3 & $2 \%$ \\
\hline (Gurak \& Lannon) & & \\
\hline Business Communication (Lehman \& Dufrene) & 1 & $1 \%$ \\
\hline Workplace Communication (Searles) & 2 & $1 \%$ \\
\hline Successful Writing at Work (Kolin) & 11 & $8 \%$ \\
\hline Write-in & 61 & $43 \%$ \\
\hline
\end{tabular}


Table 7. Results for Q17: Which of the following approaches characterize how you teach your MMPW course? (Choose all that apply)

\begin{tabular}{|c|c|c|}
\hline Teaching Approach & Responses & $\begin{array}{l}\text { Percentage of Respondents } \\
\text { Choosing an Approach }\end{array}$ \\
\hline $\begin{array}{l}\text { Teaching communication genres (e.g., } \\
\text { memos, letters, reports, etc.) }\end{array}$ & 135 & \\
\hline $\begin{array}{l}\text { Teaching professional development } \\
\text { genres (e.g., resumes, cover letters, } \\
\text { LinkedIn) }\end{array}$ & 104 & $68 \%$ \\
\hline $\begin{array}{l}\text { Connecting students to clients for writing } \\
\text { projects (e.g., collaboration with } \\
\text { institutional or industry partners) }\end{array}$ & 43 & $28 \%$ \\
\hline $\begin{array}{l}\text { Engaging students in service learning } \\
\text { projects in the community (e.g., } \\
\text { community/nonprofit partnerships) }\end{array}$ & 51 & $33 \%$ \\
\hline
\end{tabular}




\begin{tabular}{|l|l|l|}
\hline Teaching students about how to do their & 101 & $66 \%$ \\
own research about writing in workplace & & \\
contexts & & \\
\hline Engaging students in reading scholarly & 74 & \\
texts (e.g., journal articles, monographs, & & \\
research reports) and experimenting with & & \\
scholarly research methods (e.g., & & \\
ethnography, case study, interviews, etc.) & & \\
\hline Exploring case studies to create contexts & $75 \%$ \\
for writing assignments & & \\
\hline
\end{tabular}


Table 8. Results for Q82: Now choose your CENTRAL or PRIMARY approach for teaching the MMPW course (choose one)

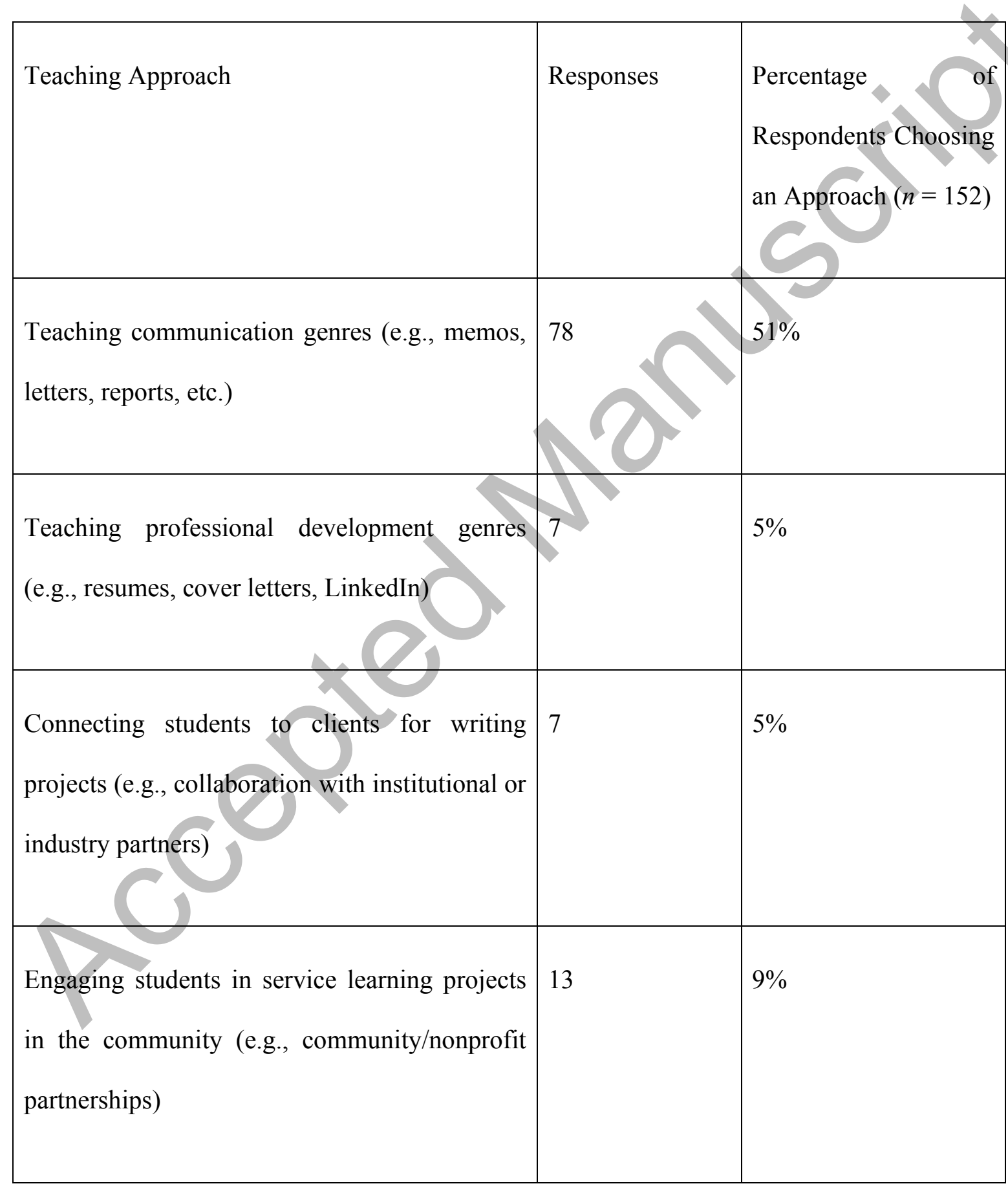




\begin{tabular}{|l|l|l|}
\hline Teaching students about how to do their own & 23 & $15 \%$ \\
research about writing in workplace contexts & & $9 \%$ \\
\hline Engaging students in reading scholarly texts & 13 & \\
(e.g., journal articles, monographs, research & & \\
reports) and experimenting with scholarly & & \\
research methods (e.g., ethnography, case & & \\
study, interviews, etc.) & & \\
\hline Exploring case studies to create contexts for & 11 & \\
writing assignments & & \\
\hline
\end{tabular}


Table 9. Subjective Assessment Slider Prompt and Average Response across All Respondents

\begin{tabular}{|l|l|}
\hline Subjective Assessment Question & Average for all respondents \\
\hline Q62. Overall Confidence in Effectiveness of MMPW & 67 \\
\hline Student Factors & \\
\hline Q38_1: Students feel more ready to write in workplace & 78 \\
\hline contexts after taking the MMPW course & \\
\hline w38_3: MMPW students are more ready to write in the & 84 \\
\hline sufficient and appropriate technological skills to write in & \\
\hline course & \\
\hline
\end{tabular}




\begin{tabular}{|l|l|}
\hline Instructor Factors & \\
\hline Q41_1: Instructors have sufficient experience and & 62 \\
training & \\
\hline Q41_4: Sections are equal in rigor and presentation of & 59 \\
\hline standard curriculum & \\
\hline Institutional Factors & \\
\hline Q41_3: MMPW instructors at your institution have & 72 \\
\hline Q41_2: Instructors have access to sufficient professional & 55 \\
\hline development & \\
\hline
\end{tabular}

*Averages rounded up to the nearest whole number. 
Table 10. Average Rating of Confidence for All Respondents Summarized by Factor

\begin{tabular}{|l|l|}
\hline Subjective Assessment Question Type & Average for all respondents $(n=154)$ \\
\hline Q62: Overall Confidence in Effectiveness of & 67 \\
the MMPW Course & \\
\hline Student factors (Q38_1-Q38_3) & 77 \\
\hline Instructor factors (Q41_1; Q41_4) & 61 \\
\hline Institutional factors (Q41_2; Q41_3) & 64 \\
\hline
\end{tabular}


Table 11. Average Level of Confidence for Student, Instructor, and Institutional Factors by Overall Confidence Level (under 50 and above 50)

\begin{tabular}{|c|c|c|c|}
\hline Subjective Assessment Question & $\begin{array}{l}\text { Average for } \\
\text { Respondents } \\
\text { under } 50 \text { for } \\
\text { Q62 }(n=30)\end{array}$ & $\begin{array}{l}\text { Average for } \\
\text { Respondents } \\
\text { over } 50 \text { for } \\
\text { Q62 }(n=124)\end{array}$ & $\begin{array}{l}\text { Average for All } \\
\text { Respondents } \\
(n=154)\end{array}$ \\
\hline $\begin{array}{l}\text { Q62. Overall Confidence in } \\
\text { Effectiveness of MMPW }\end{array}$ & $36^{*}$ & 10 & 67 \\
\hline Student Factors & & & \\
\hline $\begin{array}{l}\text { Q38_1: Students feel more ready } \\
\text { to write in workplace contexts } \\
\text { after taking the MMPW course }\end{array}$ & 58 & 82 & 78 \\
\hline $\begin{array}{l}\text { Q38_2: The MMPW course helps } \\
\text { students to acquire sufficient and } \\
\text { appropriate technological skills to }\end{array}$ & 52 & 72 & 68 \\
\hline
\end{tabular}




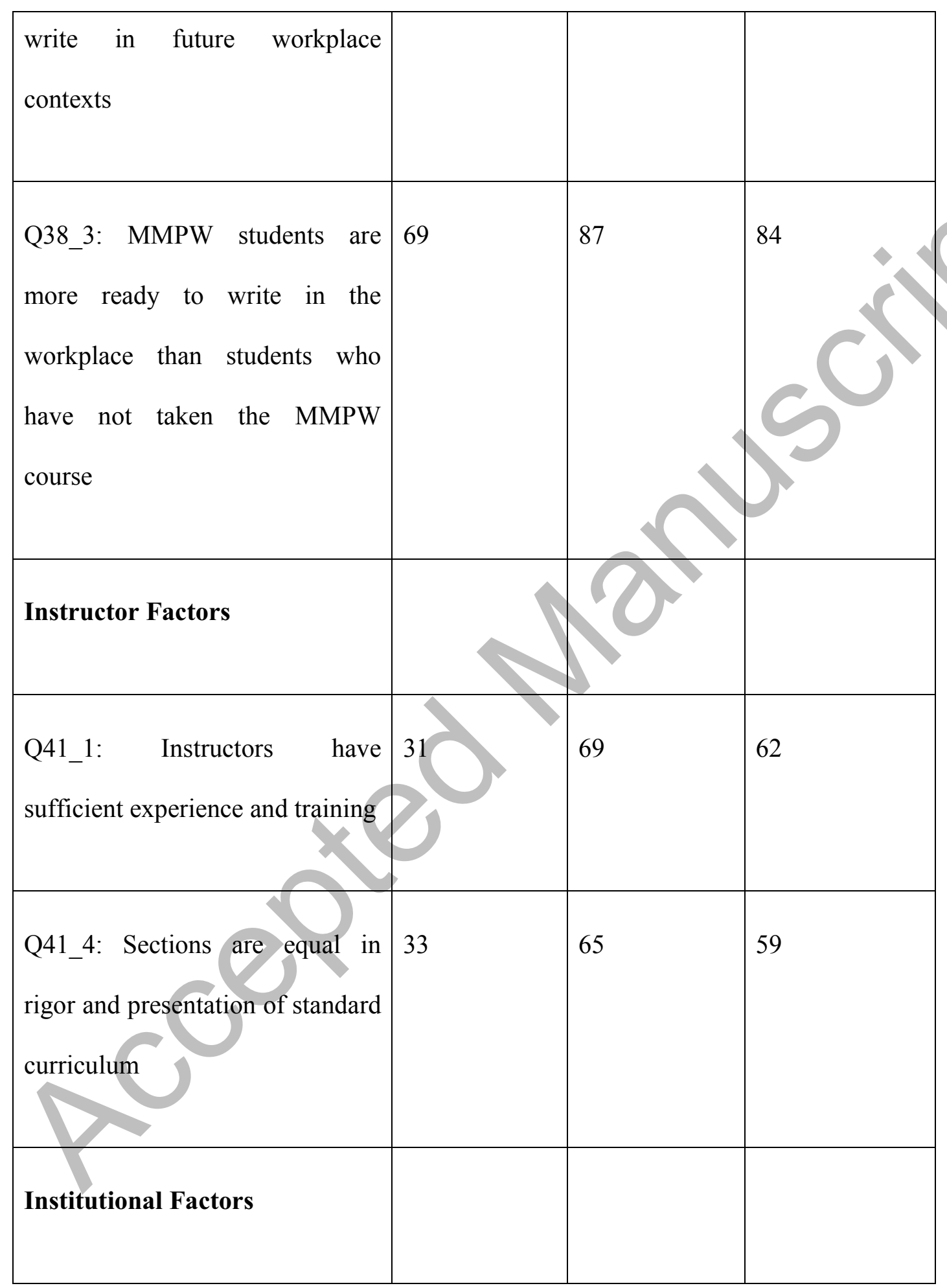




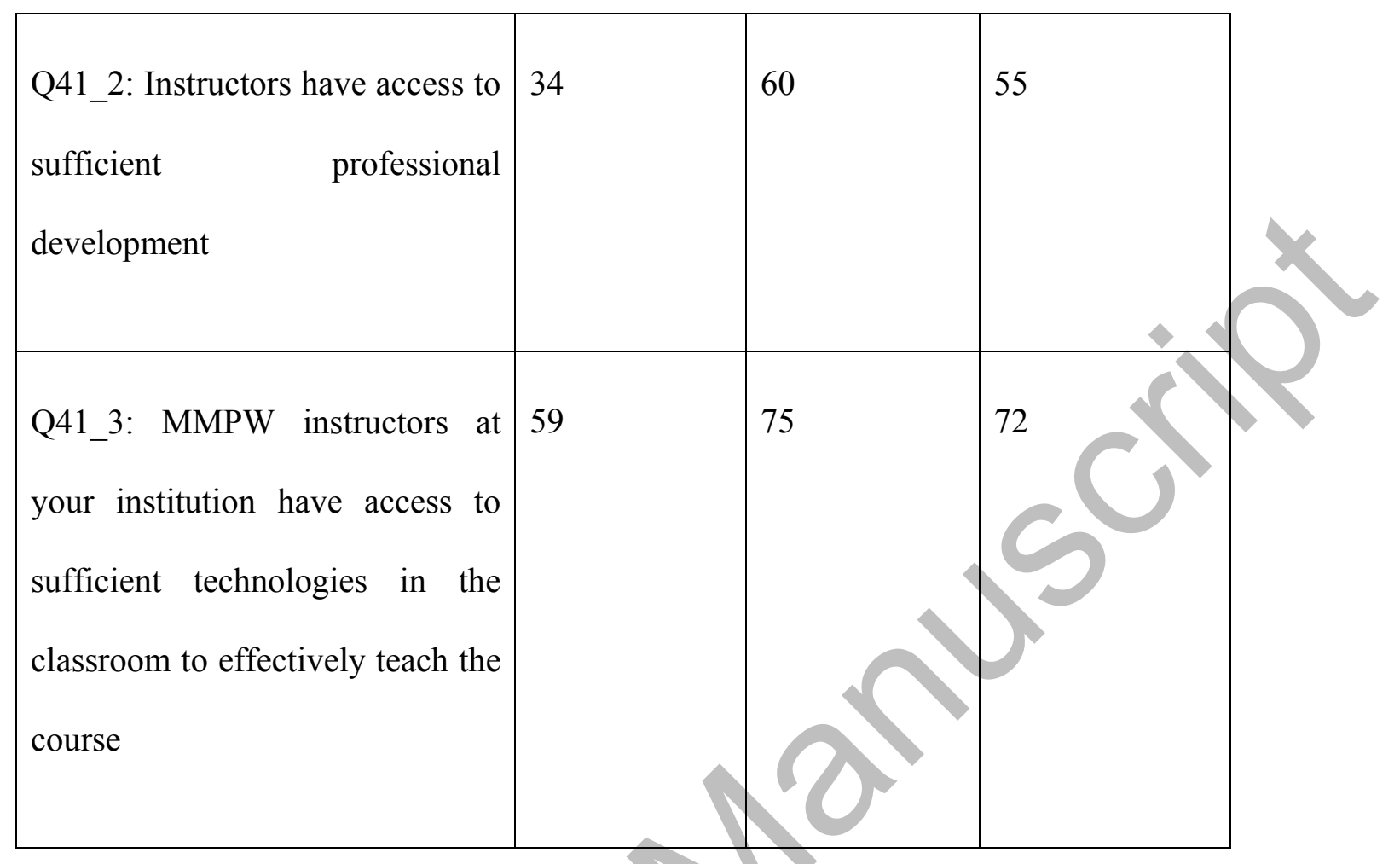

*Averages rounded up to the nearest whole number. 
Table 12. Average Rating of Confidence Summarized by Factor by Respondent Group

\begin{tabular}{|c|c|c|c|}
\hline Subjective Assessment Question Type & $\begin{array}{l}\text { Average for } \\
\text { Respondents } \\
\text { under } 50 \text { for Q62 } \\
(n=30)\end{array}$ & $\begin{array}{l}\text { Average for } \\
\text { Respondents } \\
\text { over } 50 \text { for Q62 } \\
(n=124)\end{array}$ & $\begin{array}{l}\text { Average for } \\
\text { All } \\
\text { Respondents } \\
(n=154)\end{array}$ \\
\hline $\begin{array}{l}\text { Q62: Overall Confidence in } \\
\text { Effectiveness of the MMPW Course }\end{array}$ & 36 & & 67 \\
\hline Student Factors & & 80 & 77 \\
\hline Instructor Factors & 32 & 67 & 61 \\
\hline Institutional Factor & 47 & 68 & 64 \\
\hline
\end{tabular}


Table 13. Comparing Representation of Institutional Type and Instructor Rank for the Overall Lower Confidence Group to Survey Respondents as a Whole

\begin{tabular}{|c|c|c|c|c|}
\hline & $\begin{array}{l}\text { Under-50 } \\
\text { for } \mathrm{Q} 62\end{array}$ & $\begin{array}{l}\text { Percentage } \\
\text { of Under-50 } \\
\text { Respondents } \\
(n=30)\end{array}$ & All Respondents & $\begin{array}{l}\text { Percentage of All } \\
\text { Survey Respondents } \\
(n=154)\end{array}$ \\
\hline Institutional Type & & & & \\
\hline Associate's College & 12 & $40 \%$ & 59 & $38 \%$ \\
\hline Master's College & & $17 \%$ & 30 & $19 \%$ \\
\hline Doctoral Institut & 10 & $30 \%$ & 57 & $37 \%$ \\
\hline Baccalaureate College & 1 & $3 \%$ & 6 & $4 \%$ \\
\hline Special Focus & 1 & $3 \%$ & 1 & $1 \%$ \\
\hline
\end{tabular}




\begin{tabular}{|c|c|c|c|c|}
\hline Instructor Rank & & & & \\
\hline Tenure Track & 14 & $47 \%$ & 59 & $38 \%$ \\
\hline Full-Time Non-TT & 8 & $27 \%$ & 35 & \\
\hline Adjunct/Part-Time & 6 & $20 \%$ & 31 & 20 \\
\hline Teaching Assistant & 1 & $3 \%$ & & $7 \%$ \\
\hline
\end{tabular}


Table 14. Aspect of Instructor Training by Institutional Type

\begin{tabular}{|l|l|l|}
\hline \multirow{2}{*}{ Aspect of Instructor Training } & \multicolumn{2}{|l|}{$\begin{array}{l}\text { Percentage of Respondents by } \\
\text { Institutional Type }\end{array}$} \\
\cline { 2 - 4 } & Doctoral & Associate's \\
\hline Highest Degree: PhD* & $(n=58)$ & $(n=60)$ \\
\hline Highest Degree: MA/MFA/MX* & $31 \%$ & $33 \%$ \\
\hline Have Graduate Training in PTC & $59 \%$ & $35 \%$ \\
\hline Comp. & & \\
\hline
\end{tabular}




\begin{tabular}{|ll|l|l|}
\hline Have Access $\quad$ to $\quad$ Professional & $64 \%$ & $55 \%$ \\
Development & & & \\
\hline
\end{tabular}

* Percentages for highest degree do not add up to $100 \%$ for institutional type because not all answer choices are represented in this Table (such as "JD" or "other") 
Table 15. Ranked Items that "Would Help" Improve Confidence

\begin{tabular}{|l|l|l|l|}
\hline Item Related to MMPW Course & Would & Would & Already Doing \\
& Help & Make No & $(n=154)^{*}$ \\
\hline 1. Training in contemporary workplace & Difference & $(n=154)$ & \\
technologies for instructors & 135 & 9 & \\
\hline 2. More instructors with industry & 106 & 28 & \\
\hline experience & & & \\
\hline 4. Adding an experiential dimension to & & & \\
\hline 2. More instructors with a scholarly & 106 & 23 & \\
\hline
\end{tabular}




\begin{tabular}{|c|c|c|c|}
\hline 5. Smaller class sizes & 93 & 24 & 33 \\
\hline $\begin{array}{l}\text { 6. A longer MMPW course sequence ( } 2 \\
\text { or more quarters or semesters) }\end{array}$ & 88 & 44 & 6 \\
\hline $\begin{array}{l}\text { 7. Additional classroom technologies, } \\
\text { including software and hardware }\end{array}$ & 87 & 27 & \\
\hline $\begin{array}{l}\text { 8. A set of standardized outcomes for } \\
\text { the course from a professional } \\
\text { organization such as WPA, ATTW, } \\
\text { CPTSC, or other. }\end{array}$ & & 22 & 42 \\
\hline $\begin{array}{l}\text { 9. Resources to assess the course across } \\
\text { sections on a regular basis }\end{array}$ & 81 & 25 & 37 \\
\hline $\begin{array}{l}\text { 10. New textbooks that support } \\
\text { contemporary workplace writing } \\
\text { practices }\end{array}$ & 69 & 42 & 39 \\
\hline
\end{tabular}




\begin{tabular}{|l|l|l|l|}
\hline 11. A college-, department-, or & & & \\
program-level coordinator for the & 56 & 29 & 54 \\
MMPW course & & 53 & 18 \\
\hline $\begin{array}{l}\text { 12. More sections of the course (larger } \\
\text { course enrollments) }\end{array}$ & 39 & & \\
\hline 13. Changing the department location of & & 72 & 9 \\
the course (from Business to English, & 17 & & \\
for example, or vice versa)
\end{tabular}

* Row numbers do not add up to 154 because the "not relevant" responses are not displayed. 